\title{
E9356 $1-5-95$
}

NASA Technical Memorandum 106817

AIAA-95-0720

\section{Background Noise Levels Measured in the NASA Lewis 9- by 15 -Foot Low-Speed Wind Tunnel}

Richard P. Woodward and James H. Dittmar

National Aeronautics and Space Administration

Lewis Research Center

Cleveland, Ohio

David G. Hall

NYMA, Inc.

Engineering Services Division

Brook Park, Ohio

Bonnie Kee-Bowling

National Aeronautics and Space Administration

Lewis Research Center

Cleveland, Ohio

Prepared for the

33rd Aerospace Sciences Meeting and Exhibit

sponsored by the American Institute of Aeronautics and Astronautics

Reno, Nevada, January 9-12, 1995

National Aeronautics and

Space Administration 


\title{
BACKGROUND NOISE LEVELS MEASURED IN THE NASA LEWIS 9- BY 15-FOOT LOW-SPEED WIND TUNNEL
}

\author{
Richard P. Woodward and James H. Dittmar \\ National Aeronautics and Space Administration \\ Lewis Research Center \\ Cleveland, Ohio 44135 \\ David G. Hall \\ NYMA Technology, Inc. \\ Exngineering Services Division \\ Brook Park, Ohio 44142 \\ and \\ Bonnie Kee-Bowling \\ National Aeronautics and Space Administration \\ Lewis Research Center \\ Cleveland, Ohio 44135
}

\begin{abstract}
$\underline{\text { Abstract }}$
The acoustic capability of the NASA Lewis 9- by 15 -Foot Low Speed Wind Tunnel has been significantly improved by reducing the background noise levels measured by in-flow microphones. This was accomplished by incorporating streamlined microphone holders having a profile developed by researchers at the NASA Ames Research Center. These new holders were fabricated for fixed mounting on the tunnel wall and for an axially traversing microphone probe which was mounted to the tunnel floor. Measured in-flow noise levels in the tunnel test section were reduced by about $10 \mathrm{~dB}$ with the new microphone holders compared with those measured with the older, less refined microphone holders. Wake interference patterns between fixed wall microphones were measured and resulted in preferred placement patterns for these microphones to minimize these effects. Acoustic data from a model turbofan operating in the tunnel test section showed that results for the fixed and translating microphones were equivalent for common azimuthal angles, suggesting that the translating microphone probe, with its significantly greater angular resolution, is preferred for sideline noise measurements. Fixed microphones can provide a local check on the traversing microphone data quality, and record acoustic performance at other azimuthal angles.
\end{abstract}

\section{Introduction}

The NASA Lewis 9- by 15-Foot Low Speed Wind Tunnel provides an anechoic test environment at flow speeds up to 0.20 Mach. The tunnel is located in the return leg of the 8by 6-Foot Supersonic Wind Tunnel (fig. 1). The tunnel walls, floor, and ceiling are lined with acoustic boxes resulting in anechoic free field conditions above $250 \mathrm{~Hz} .{ }^{1,2}$ The tunnel was recently improved with additional upstream acoustic treatment to further suppress tunnel drive noise. Up- stream flow straightening screens were added to reduce test section airflow turbulence. However, there remained concern that ambient tunnel background noise levels (at $0.20 \mathrm{Mach}$ ) might be too high to correctly measure takeoff/ approach noise of advanced technology ducted propulsors at certain operating conditions. Tunnel drive compressors, flow noise, and microphone holder self noise induced by airflow over the holder, among others, contribute to the total ambient background noise level.

For discussion purposes in this report, the microphone "holder" refers to the structure including the support airfoil and extension tube to the actual microphone. In some instances these holders were mounted on a traversing microphone probe. Standard $0.64 \mathrm{~cm}(0.25 \mathrm{in}$.) microphones were used in this study.

Recent internal work at the NASA Ames Research Center, under the direction of researchers Paul Soderman and Christopher Allen have shown that improvements in the in-flow microphone holder can significantly lower the microphone holder self noise. A representative machined aluminum microphone holder from NASA Ames was used in the $9 \times 15$ noise study. Figure 2 shows sketches of the original microphone holder which has been used for all acoustic work through 1993, an extruded streamlined tube holder, and the borrowed Ames holder. The Ames holder was designed for only a $30.5 \mathrm{~cm}(1 \mathrm{ft})$ projection into the airflow, necessitating a wooden streamlined extension to place the microphone

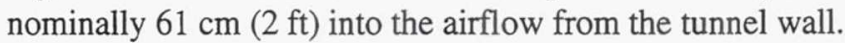
One characteristic of the improved microphone holders is an upstream extension tube with a smooth transition to the microphone assembly. Of these designs, the Ames holder showed the lowest microphone self noise in the tunnel flow. A master mold of the Ames holder was made, and similar fiberglass holders were fabricated for use in the $9 \times 15$ tunnel. Figure 3 is a side view photograph of a new fiberglass Amesprofile microphone holder. These holders were used for the 
wall-mounted microphones (nominally $61 \mathrm{~cm} \mathrm{(24} \mathrm{in.)} \mathrm{from}$ the tunnel wall) and for the translating probe with a longer extended holder to place the microphone at the tunnel vertical centerline. A typical microphone installation in the tunnel test section is shown in figure 4.

The translating microphone probe acquires sideline "flyover" noise directivities of the test article. This probe has a streamlined fairing over the traversing mechanism, and a fiberglass streamlined microphone holder sufficiently long to place the microphone at the tunnel vertical centerline. Probe operation is achieved with a computer-driven data acquisition system with digital positioning capability. Thus, the probe pauses for sequential stationary data acquisition at prescribed axial locations.

The objectives of this study were to document emptytunnel noise level reductions achieved by the Ames-profile microphone holders and to evaluate data acquisition procedures for data quality and repeatability.

\section{Procedure}

In-flow noise measurements were obtained from 0.05 to 0.20 tunnel Mach number, normally in 0.05 incremental steps, but with some investigative finer resolution. Most of the acoustic calibration was performed at the maximum practical tunnel speed of $0.20 \mathrm{Mach}$, which has been used for measuring takeoff/approach noise. Fixed microphones were installed on both tunnel side walls and (for limited investigations, not shown on fig. 4) on the tunnel floor. The floor mounted translating microphone probe provided a more detailed survey of the axial noise distribution.

Acoustic data were acquired in two successive constant bandwidth formats, and then post processed to generate $1 / 3$ rd octave spectra. The fine resolution constant bandwidth data had a $5.9 \mathrm{~Hz}$ bandwidth over a usable range of 0 to $8 \mathrm{KHz}$. The coarse resolution data had a $117.2 \mathrm{~Hz}$ bandwidth and $80 \mathrm{KHz}$ useable range (see table I).

It was necessary to mount the fixed microphones at "hard" points on the tunnel wall. This usually required the use of a mounting board which was secured to the tunnel wall hard points, with the fixed microphone holders fastened to this board. The board was foam covered to minimize acoustic reflections. The fixed microphone holders were staggered vertically to minimize interaction with wakes from upstream microphone holders.

A starter pistol was used as an impulse noise source to quantify acoustic reflections from tunnel structures upstream and downstream from the test section. Noise measurements from a model turbofan were used to compare data measured by the fixed and translating microphones. Data were acquired from this noise source using various numbers of data ensembles to quantify data quality and repeatability.

\section{Results and Discussion}

\section{Empty tunnel calibration}

Figure 5 shows representative background noise levels at 0.20 Mach in the $9 \times 15$ tunnel. A curve is also included showing noise levels measured in a 0.20 Mach flow at the Boeing LSAF facility. ${ }^{3}$ The data are presented "asmeasured" with no corrections for attenuation. A significant decrease in the microphone self-noise is seen with the borrowed Ames holder and the essentially equivalent fiberglass clone of the Ames holder. Data for the fiberglass holder were taken with the translating microphone probe. The machined Ames holder extended only $30.5 \mathrm{~cm}$ (1 ft) into the airflow, requiring an additional streamlined extension to bring the

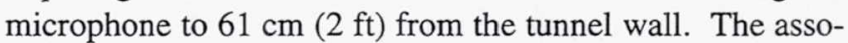
ciated disjoint between the Ames holder and mount extension may account for its higher self noise levels relative to the fiberglass clone in the region of 800 to $1600 \mathrm{~Hz}$. These measured levels are not quite as low as those published for LSAF, suggesting that further improvement may be possible.

The Ames-profile fiberglass mounts were fitted with upstream microphone extension tubes to minimize acoustic interference with the mount airfoil. Two lengths of extension tubes were fabricated for these tests. The shorter extension tube positioned the microphone $40.6 \mathrm{~cm}$ (16 in.) upstream of the airfoil centerline. The longer length tube positioned the microphone $55.9 \mathrm{~cm}$ (22 in.) ahead of the airfoil centerline. Figure 6 compares background noise measured at the same wall mount location for the two extension tube lengths. Data are shown for four tunnel speeds. In each case noise levels measured with the shorter extension tube are slightly higher (perhaps due to closer proximity to the microphone holder airfoil). Use of the shorter tubes makes microphone placement in the tunnel somewhat easier (holder to holder interference), and may be preferred if this is a concern and slightly higher self-noise levels can be tolerated. The data for the fiberglass clone Ames-profile holder in figure 5 was with the short extension. These results could possibly be even more favorable with the longer extension in place.

Earlier work in the $9 \times 15$ tunnel showed that the acoustic flight effect (a significant lowering of the fan tone due to reduction in ingestion of elongated turbulence eddies) essentially takes place at all speeds above $0.05 \mathrm{Mach}^{4}$ (fig. 7). Figure 8 shows about a $20 \mathrm{~dB}$ reduction in measured background noise when the tunnel Mach is reduced from 0.20 to 0.10 . In fact, the $9 \times 15$ background levels at 0.10 Mach compare favorably with published LSAF levels outside of the $(0.20 \mathrm{Mach})$ free jet. Thus, it may be desirable to test future low-noise fans at less than 0.20 Mach if corresponding aerodynamic conditions are acceptable. 
The $8 \times 6 / 9 \times 15$ tunnel drive runs at essentially a constant speed. Tunnel speed in the $9 \times 15$ is controlled by manipulation of upstream (out bleed) and downstream (compressor flow makeup) doors (see fig. 1). Thus, noise reductions measured at lower tunnel speed are due to flow velocity reductions, not changes in the tunnel drive noise.

There was some concern that upstream/downstream reflections might degrade the test section acoustic environment. Reflections at frequencies below $5000 \mathrm{~Hz}$ were investigated using a starter pistol as an impulse noise source. As shown in figure 9, reflections from the upstream cooler (and possibly the flow screens) and the downstream tunnel corner were identified. The magnitude of the reflection from the upstream cooler was at least $24 \mathrm{~dB}$ below that of the initial impulse. This shows that upstream/downstream reflections (at least at the lower frequencies) are not a problem in the $9 \times 15$ test section.

The $9 \times 15$ tunnel has longitudinal slots in the test section (see fig. 4) to help control tunnel wall interference effects. It was thought that airflow entering these slots may increase flow noise. However, covering these slots with boards faced with sound absorbing foam had no detectable effect on the noise levels, thus the slots will remain open as part of the tunnel architecture for future tests.

Aerodynamic interaction between microphone holders can be a problem in wind tunnel acoustic measurements if care is not taken to ensure that the microphones are outside the wakes from upstream obstructions. Tests were conducted in the $9 \times 15$ LSWT with several fiberglass microphone holders mounted at various relative positions on the tunnel wall. For simplicity, a Cartesian $(\mathrm{x}, \mathrm{y}, \mathrm{z})$ coordinate system was used for locating the downstream microphone as sketched in figure 10. The downstream microphone position is referenced to the mid-chord airfoil centerline of the upstream microphone holder. The half-angle is designated as " $\theta_{12}$ " between probe holders 1 and 2 .

Results indicate that a half-angle more than $5^{\circ}$ must be observed to avoid wake interaction with an upstream microphone probe (fig. 11), for this particular support strut geometry. A total of three microphones were used in this wake interference study. Relative holder angles $(\theta)$ are indicated relative to all upstream microphone holders. Results shown in figure 11 show that a half-angle of about $5^{\circ}$ may, or may not, be a problem for a particular installation. A half-angle of at least $7^{\circ}$ will be observed for future test programs to avoid this potential problem.

These tests also revealed a strongly-propagating disturbance emanating from the tip region of the microphone holder. This apparent disturbance significantly increased the noise levels directly downstream-even at spacings of $406 \mathrm{~cm}$ (160 in.) or more (fig. 12). However, remounting the downstream probe an additional $10 \mathrm{~cm}$ (4 in.) away from the tunnel wall effectively eliminated this wake interaction problem. The translating microphone probe inherently avoids upstream microphone holder wake interaction while offering a large number (currently 48) of incremental sideline measuring positions.

Figures 13 and 14 show the tunnel background noise levels at $0.20 \mathrm{Mach}$ as a function of axial position in the test section. Data were taken using the translating probe with the Ames-profile fiberglass microphone holder. Figure 13 shows $1 / 3$ rd octave spectra for five axial locations in the tunnel test section. Noise levels at lower frequencies are seen to decrease with distance into the test section. This attenuation with distance into the test section is most significant in the frequency range where the treatment is most effective, ie., 500 to $5000 \mathrm{~Hz}$. Figure 14 shows this variation with tunnel axial position at four representative 1/3rd octave frequencies. There is a about a $5 \mathrm{~dB}$ noise level reduction toward the downstream end of the test section at $1000 \mathrm{~Hz}$, and $2 \mathrm{~dB}$ reduction at $500 \mathrm{~Hz}$. At higher frequencies of 8000 and $16000 \mathrm{~Hz}$ the sound level shows a local increase of about 3 $\mathrm{dB}$ toward the middle of the test section. The reason for this noise increase may relate to noise generation by airflow over the wall mounted microphone holders being measured by the translating microphone probe.

It is not clear if measured noise levels with the fiberglass microphone holders are controlled by holder self-noise or represent ambient tunnel levels. The observed progressive noise decrease with distance into the test section at 500 and $1000 \mathrm{~Hz}$ suggests that noise at these lower frequencies may be test section ambient noise levels which are progressively attenuated by the tunnel wall treatment. If these noise levels were generated as microphone holder self noise, there should be no significant level change with tunnel position.

It is well known that relatively minor flow disturbances can generate significant acoustic tones. A tone was detected during the calibration process whose frequency appeared to be a function of tunnel speed, with maximum levels near the center of the tunnel test section. The tone level was $10 \mathrm{~dB}$ or more above the spectral broadband and was most prominent at speeds below $0.20 \mathrm{Mach}$ (fig. 15). The cause of this tone was eventually traced to a vortex flow from a total pressure rake mounted from the tunnel ceiling at approximately the center of the test section (a significant distance from the microphones). The probe body extended $31.8 \mathrm{~cm}$ (12.5 in.) into the flow and had a $5.5 \mathrm{~cm}$ (2.2 in.) chord. Vortex trips were added to the rake trailing edge. This modification eliminated the extraneous tone. A similar tone problem existed for a total pressure probe located at the test section leading edge, which was likewise corrected. 
Data acquisition procedures for a model turbofan

Tunnel acoustic data presented up to this point have been for an acoustically treated test section with only microphone instrumentation present. The following discussion is presented to indicate acoustic performance in the $9 \times 15$ LSWT with an operating test article as a noise source.

One concern that must be addressed in future experiments is the minimum allowable number of spectral ensembles used to compute the sound power level. The number of ensembles must be large enough to minimize statistical errors and to insure that any short-term acoustic fluctuations in the test article are accounted for. Fewer ensembles result in a shorter test time and significant cost savings.

A test was conducted for determining a suitable number of data ensembles with the model turbofan held at constant speed. Data were taken from an upstream wall microphone using $16,24,32$, and 44 ensembles. Data are shown for two surveys at each ensemble number. Acquisition time varied from 3.07 to $8.09 \mathrm{sec}$. The results (fig. 16) show excellent agreement for all four cases. However, there is slightly better repeatability for 24 or more ensembles at some broadband frequencies.

The model was then held at the same speed while the translating microphone was used to record data at each of 48 axial locations. Figure 16 showed that a significant tone was generated by the model at $4000 \mathrm{~Hz}$. Figure 17(a) shows the directivity of this tone for the traversing microphone with 10,16, and 24 ensembles at each stop. The 24 ensemble case was run twice for comparison. The agreement between all cases was very good. The use of 10 ensembles resulted in an acquisition time of $1.99 \mathrm{sec}$ at each traverse stop point (6.73 min for the complete survey). Figure 17(b) presents corresponding data for broadband data at $2500 \mathrm{~Hz}$. The repeatability results at $2500 \mathrm{~Hz}$ show somewhat more variation than those for the $4000 \mathrm{~Hz}$ tone, however this variation is quite small for 24 ensembles. For future experiments, 24 ensembles are recommended at each traverse stop location. This results in a sampling time of $4.5 \mathrm{sec}$ at each stop and a total traverse time of $10.0 \mathrm{~min}$ (see table II). In view of the results presented herein, this should provide an accurate measurement of the acoustic signature of most test articles.

Noise measurements from a model turbofan were used to show the equivalence of data acquired by the fixed and translating microphone probes. Data from this noise source was also used to assess data quality as a function of number of data ensembles. Clearly, the acoustic stability of the noise source also enters into such a comparison, it being desirable to acquire data over a sufficient length of time to average out short term variations in sound power level. Acoustic data were acquired with 12 fixed wall microphones and the translating microphone probe. The fixed microphones were mounted so as to minimize effects of upstream microphone holder disturbances (i.e., half-angle greater than $7^{\circ}$, see fig. 10). The side-line distance to the translating microphone was $224.5 \mathrm{~cm}$ (88.4 in.), while the fixed microphone sidelines were an additional 6.0 to $16.2 \mathrm{~cm}$ ( 2.4 to $6.4 \mathrm{in}$.) further away. Data for the fixed microphones were acquired with the track microphone fully aft to avoid wake interactions.

The translating microphone probe provides a fine sideline resolution of the acoustic data while avoiding acoustic interference with upstream microphone holders. The close sideline proximity of the fixed and translating microphones for the model turbofan tests afforded an excellent opportunity to compare data acquired by the two microphone installations. Representative upstream and downstream spectral comparisons are presented in figure 18. These data are for locations where the fixed microphone was at essentially the same azimuthal angle (distance above the tunnel floor) as the translating microphone. The data comparison is quite good, indicating that data taken with the translating microphone probe is comparable in quality with that taken with fixed microphones. Small differences in the spectra are likely due to slightly different microphone azimuthal angles.

In order to minimize upstream microphone holder wake interference, it is usually necessary to vertically spread the fixed wall microphone array, resulting in a variety of azimuthal angles for the fixed microphones. The acoustic signature of test articles may have an azimuthal component. A vertically-displaced array of fixed wall microphones may not accurately measure flyover noise (sideline) directivity for a particular azimuthal angle. It is suggested that the greatest benefit of fixed wall microphones would be to verify data for the translating microphone probe at a selected sideline angle, and to investigate azimuthal directivities in the noise field at selected sideline angles.

\section{Concluding Remarks}

The acoustic capability of the NASA Lewis 9- by 15 - Foot Low Speed Wind Tunnel has been significantly improved by reducing the background noise levels measured by in-flow microphones. This was accomplished by incorporating streamlined microphone holders having a profile developed by researchers at the NASA Ames Research Center. These new holders were fabricated for fixed mounting on the tunnel wall and for an axially traversing microphone probe which was mounted to the tunnel floor. Measured in-flow noise levels in the tunnel test section were reduced by about $10 \mathrm{~dB}$ with the new microphone holders compared with those measured with the older, less refined microphone holders. It was shown that tunnel operation at lower tunnel speeds would significantly reduce test section background noise levels and might be an option for testing future, exceptionally quiet, test articles.

Tests were conducted to evaluate the acoustic effect of flow disturbances between fixed microphone holders. It was shown that at least a $7^{\circ}$ half-angle should be maintained with upstream holders. It was also shown that a flow disturbance propagates directly downstream from the microphone holder with minimal attenuation. Therefore, downstream microphones were further extended from the tunnel wall to avoid wake aeroacoustic interaction. These considerations dictate 
acceptable placement of fixed wall microphones and limit the possible number of microphones.

Acoustic investigations with a model turbofan as a noise source show that an axially translating microphone probe is preferable to fixed wall microphones to accurately measure flyover noise directivities. The translating probe eliminates concern about wake interaction with upstream microphone holders. Also, the large number of incremental data positions used with the translating probe provide a much finer resolution of the sideline acoustic directivity than would be possible with a fixed wall microphone array.

There was concern that the data sample length at each angular location would be compromised for the translating probe due to constraints on total traverse times, and the large number of sequential data positions chosen. Comparisons were made between fixed microphone and translating microphone probe data at comparable tunnel positions. It was shown that 24 data ensembles provide repeatable acoustic spectra for the model turbofan and that data acquired by fixed or translating microphones is equivalent. It is suggested that the greatest value of fixed wall microphones is to verify data at a selected sideline position and to explore azimuthal directivity.

\section{$\underline{\text { References }}$}

1. Dahl, M.D., and Woodward, R.P., "Acoustical Evaluation of the NASA Lewis 9- by 15-Foot Low Speed Wind Tunnel," NASA TP-3274, November, 1992.

2. Dahl, M.D., and Woodward, R.P., "Comparison Between Design and Installed Acoustic Characteristics of NASA
Lewis 9- by 15-Foot Low-Speed Wind Tunnel Acoustic Treatment," NASA TP-2996, April, 1990.

3. Allen, R.M., and Reed, D.H., "Development of the Boeing Low Speed Aeroacoustic Facility (LSAF)," DGLR/ AIAA 92-02-030, May, 1992.

4. Chestnutt, D., "Flight Effects of Fan Noise," NASA CP-2242, January, 1982.

TABLE I.-DATA ACQUISITION CHARACTERISTICS

\begin{tabular}{|l|c|c|c|c|c|}
\hline $\begin{array}{c}\text { Analysis } \\
\text { range }\end{array}$ & $\begin{array}{c}\text { Samples/ } \\
\mathrm{sec}, \\
\mathrm{K}\end{array}$ & $\begin{array}{c}\text { Samples/ } \\
\text { ensemble }\end{array}$ & $\begin{array}{c}\text { Useful } \\
\text { bandwidth } \\
(3: 1), \\
\mathrm{kHz}\end{array}$ & $\begin{array}{c}\text { Lines in } \\
\text { spectrum }\end{array}$ & $\begin{array}{c}\text { Bandwidth } \\
\text { (per line), } \\
\mathrm{Hz}\end{array}$ \\
\hline High & 240 & 2048 & 80 & 680 & 117.2 \\
Low & 24 & 4096 & 8 & 1360 & 5.9 \\
\hline
\end{tabular}

TABLE II.-ACOUSTIC DATA ACQUISITION TIMES

[Time in each traverse stop is based on A/D converter sampling rates and number of samples/ensemble.]

\begin{tabular}{|c|c|c|}
\hline $\begin{array}{c}\text { Number of } \\
\text { ensembles }\end{array}$ & $\begin{array}{c}\text { Data } \\
\text { acquisition } \\
\text { interval, sec }\end{array}$ & $\begin{array}{c}\text { Total } \\
\text { traverse } \\
\text { time for 48 } \\
\text { positions, } \\
\text { min }\end{array}$ \\
\hline 10 & 1.99 & 6.73 \\
16 & 3.07 & 8.33 \\
24 & 4.50 & 10.00 \\
32 & 5.87 & no data \\
44 & 8.09 & no data \\
\hline
\end{tabular}




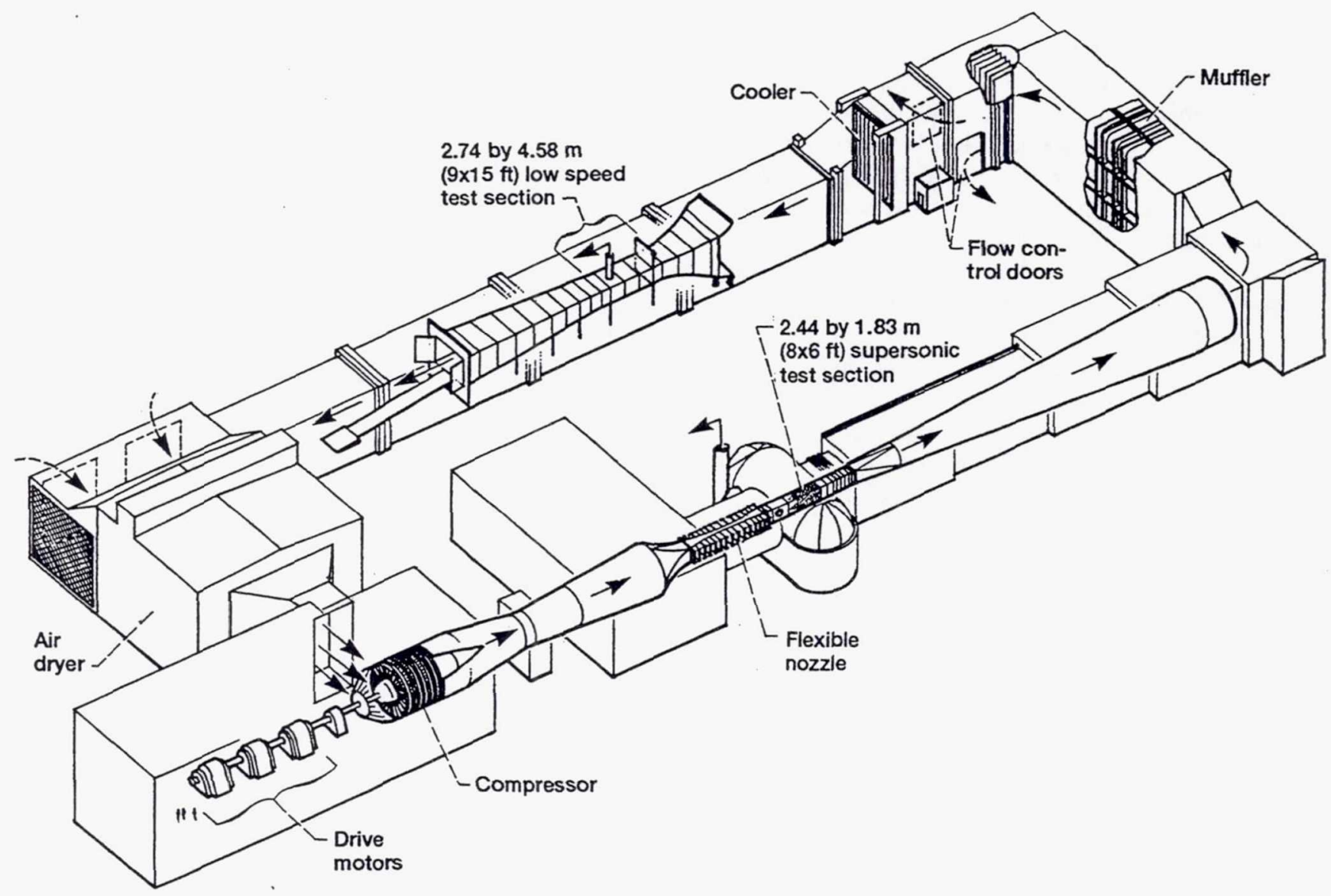

(a)

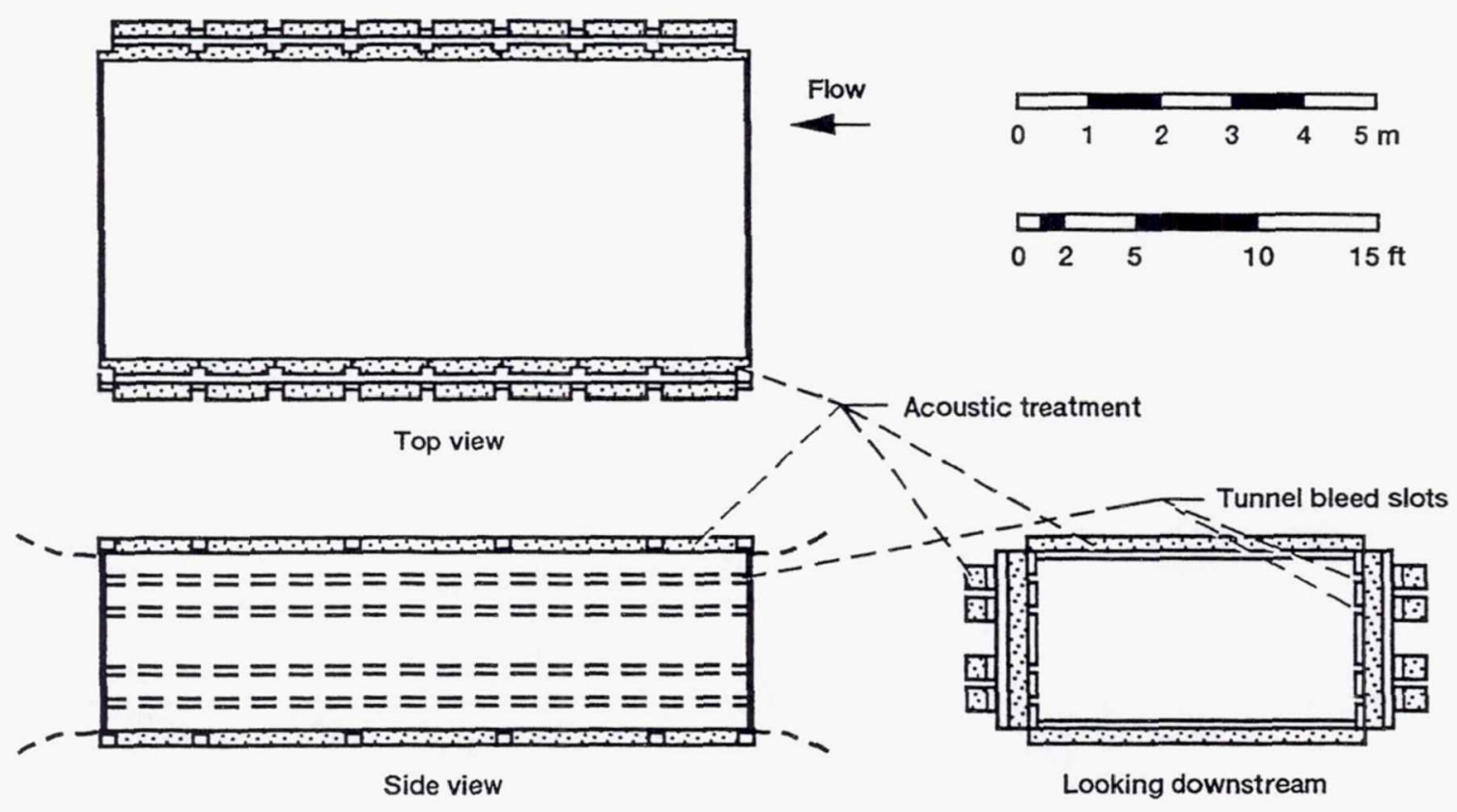

(b)

Figure 1.-Design of NASA Lewis 9x15 anechoic wind tunnel. (a) NASA Lewis 9- by 15-Foot and 8- by 6-Foot Wind Tunnels.

(b) Sectional views of the 9 - by 15-Foot Low-Speed Wind Tunnel test section. 


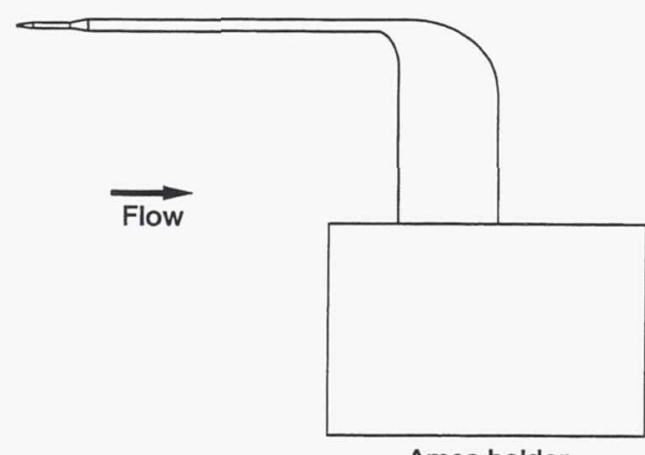

Ames holder

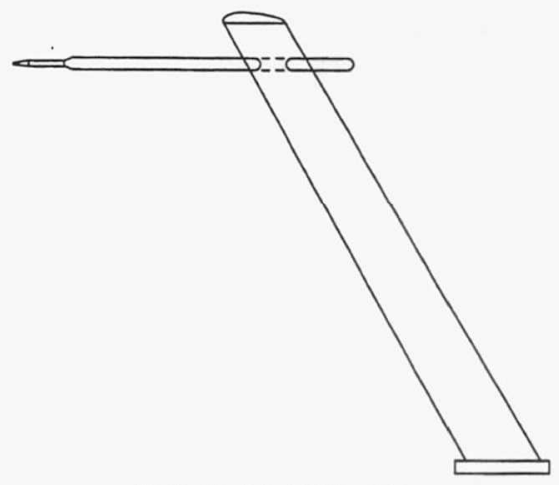

Extruded LeRC holder

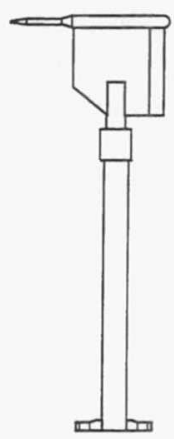

Original

LeRC holder

Original LeRC holder: Minimal streamlining -- significant flow disturbances. Extruded LeRC holder: Much less flow disturbance/lower self noise; however, may have significant downstream wake.

Ames holder:

Precision airfoil streamlining -- lowest self noise.

Supplied holder extended only $1 \mathrm{ft}$ into flow, requiring $1 \mathrm{ft}$ wooden airfoil extension.

Figure 2.-Test microphone holders.

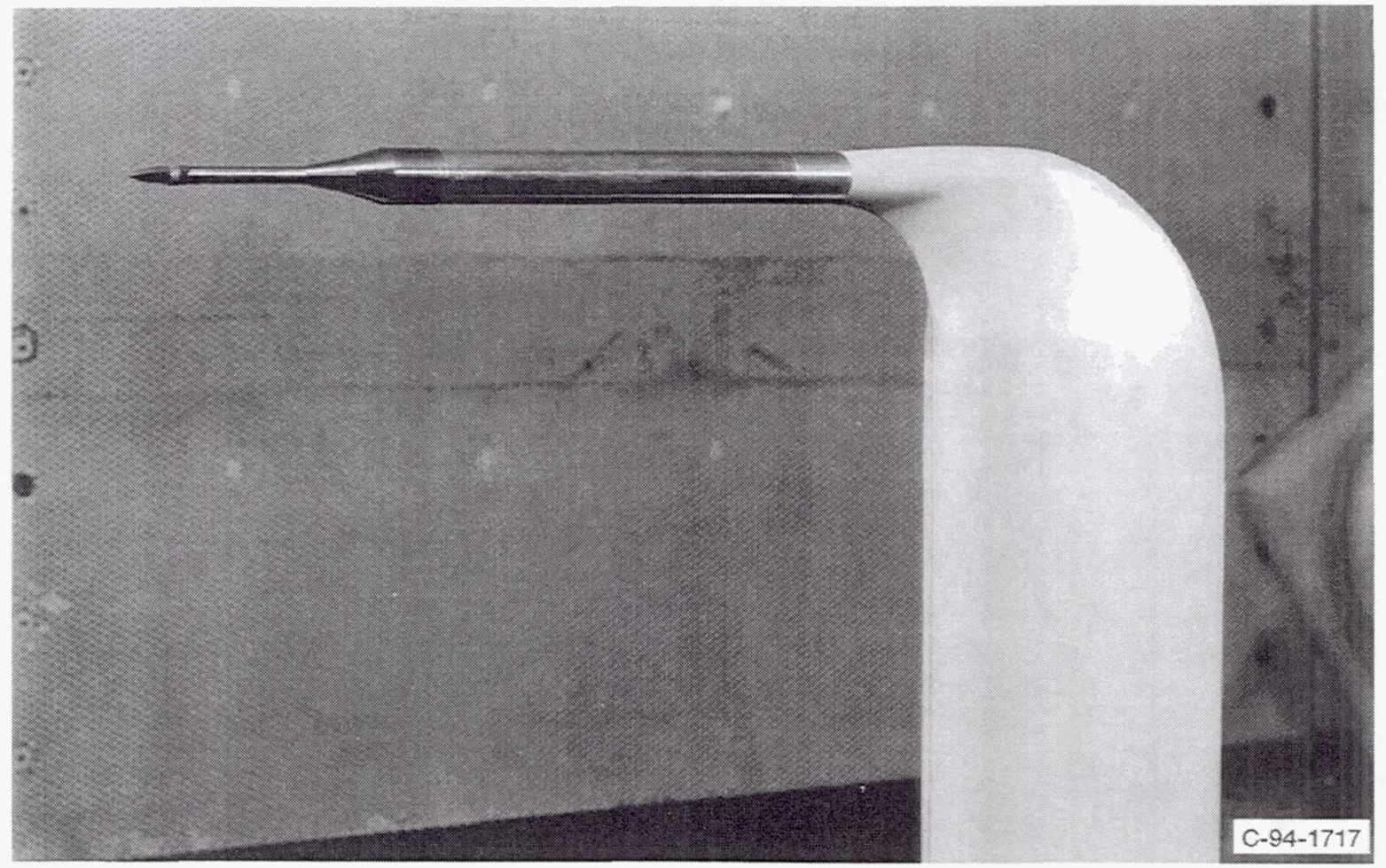

Figure 3.-Photograph of streamlined microphone holder. 


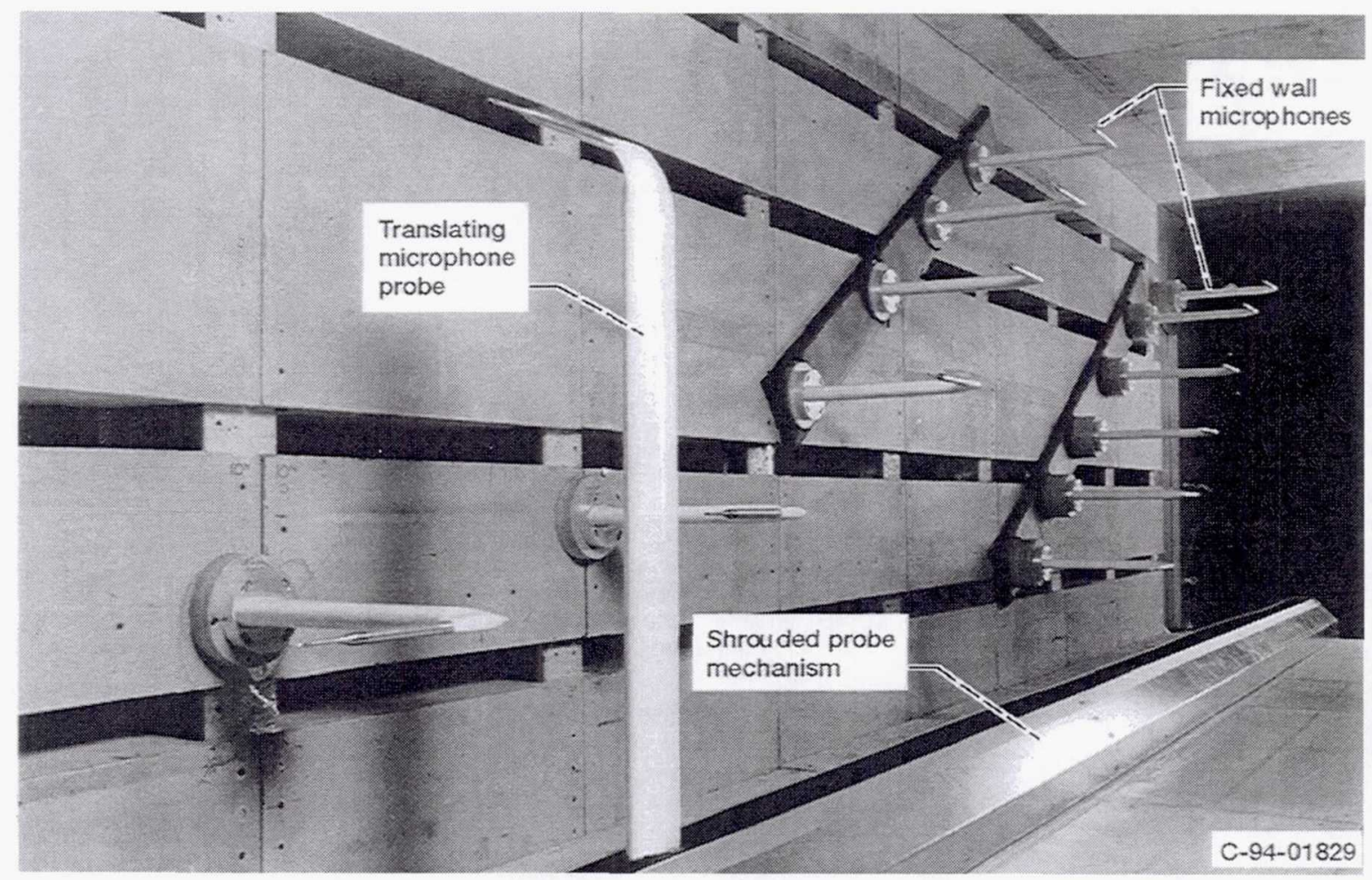

Figure 4.-Photograph of installed fixed wall microphones and traversing probe (Ames-profile fiberglass holders).

$1 / 3 \mathrm{rd}$

OC T A VE

SOUND

PRESSURE

LEVEL, dB

MI CROPHONE MOUNT

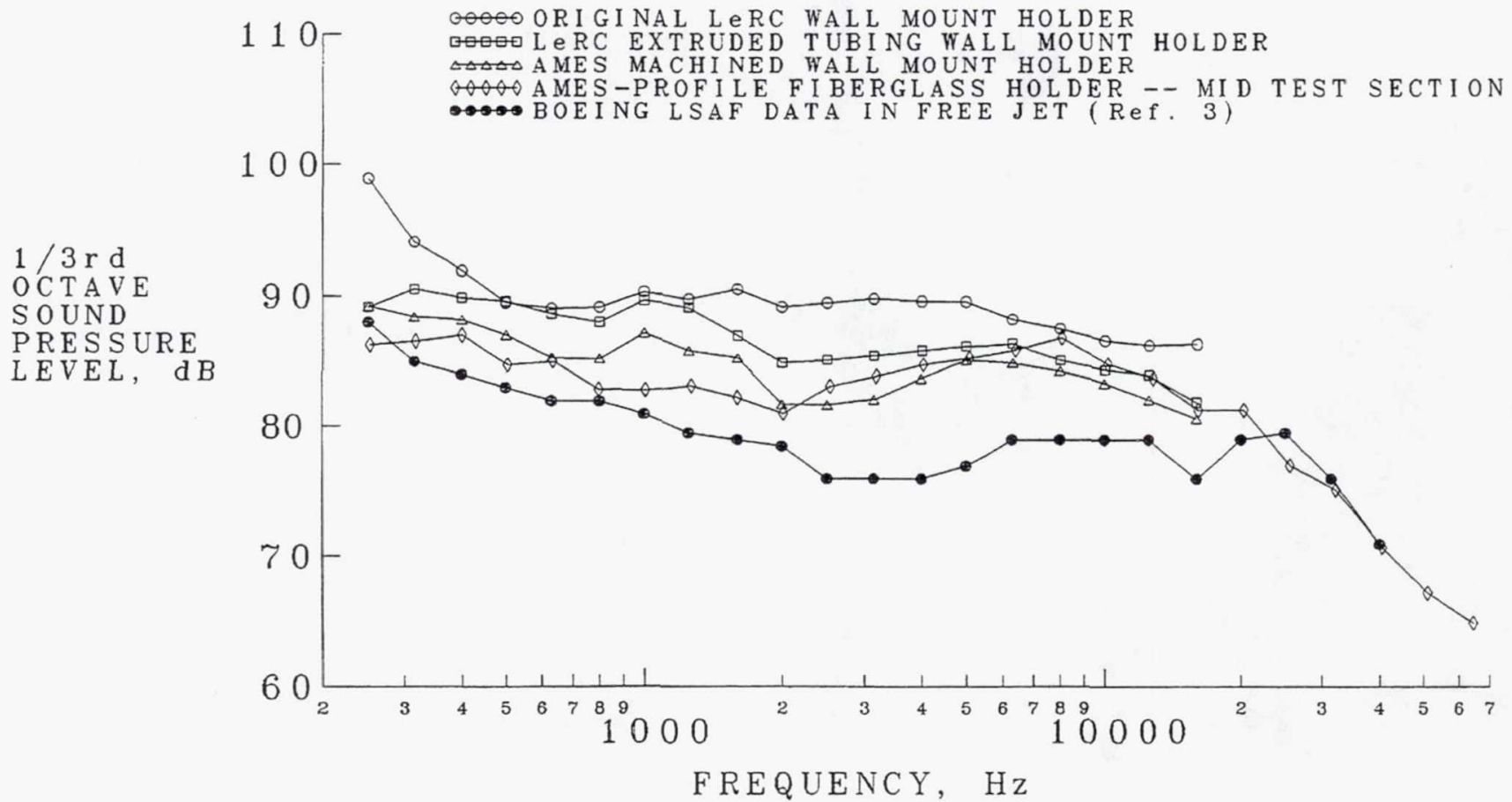

Figure 5.-Representative background noise levels in the $9 \times 15$ LSWT (0.20 M). 


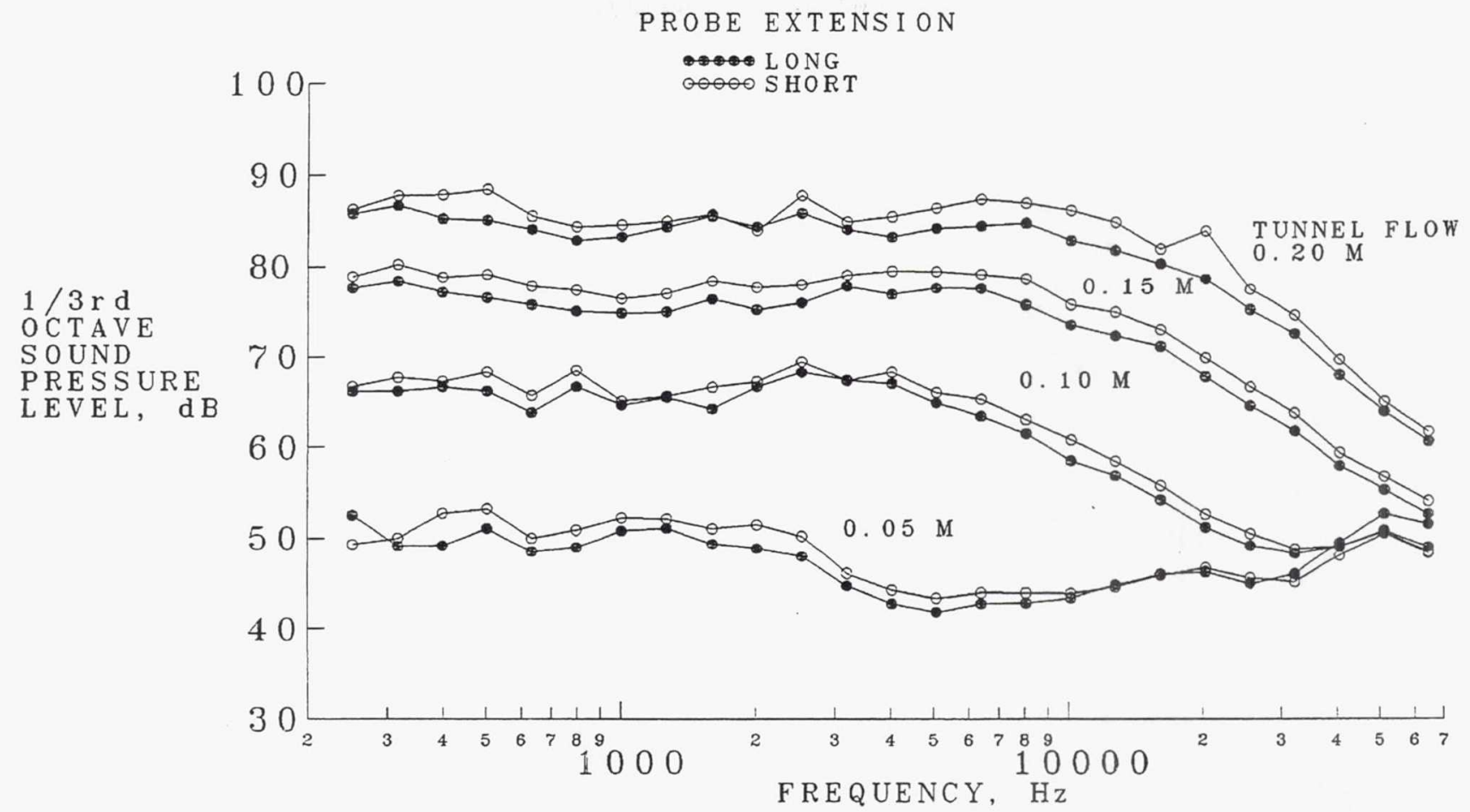

Figure 6.-Effect of microphone holder upstream extension at four tunnel speeds (wall mount, Ames-profile fiberglass holders).

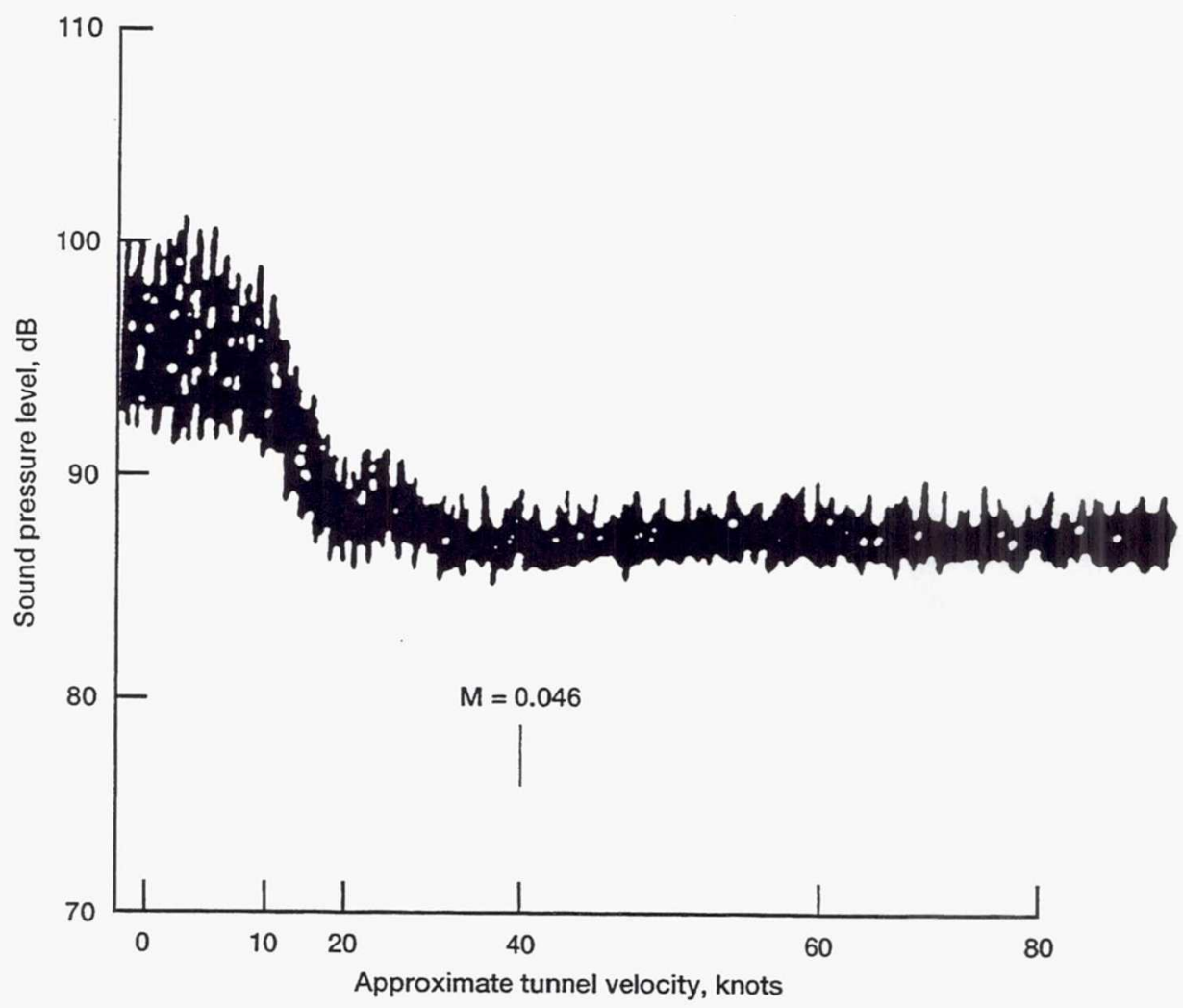

Figure 7.-Flight effect on fan blade passage tone level (ref. 4). 


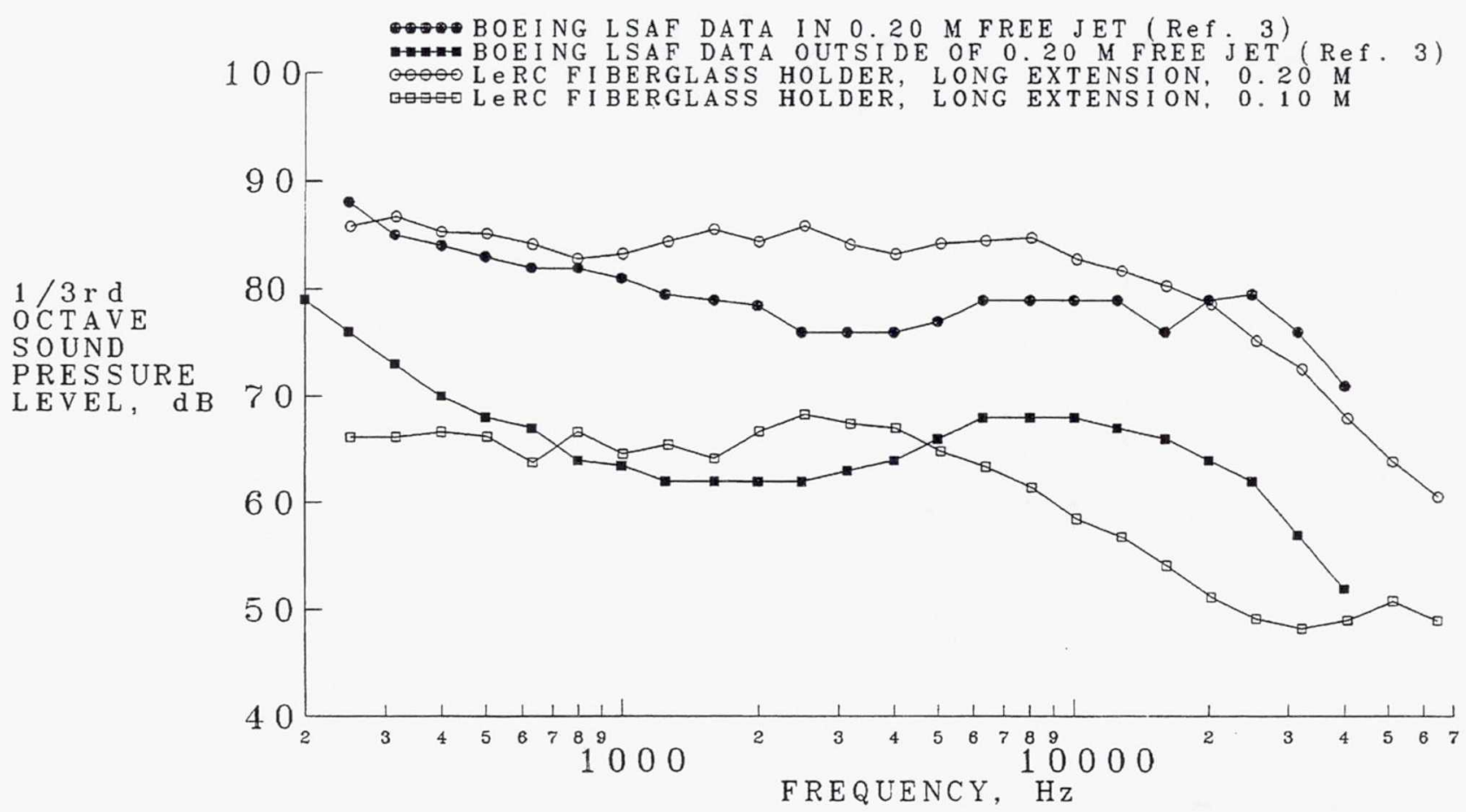

Figure 8.-Reductions in tunnel background noise levels with reduced tunnel velocity (wall mount, Ames-profile fiberglass holder).

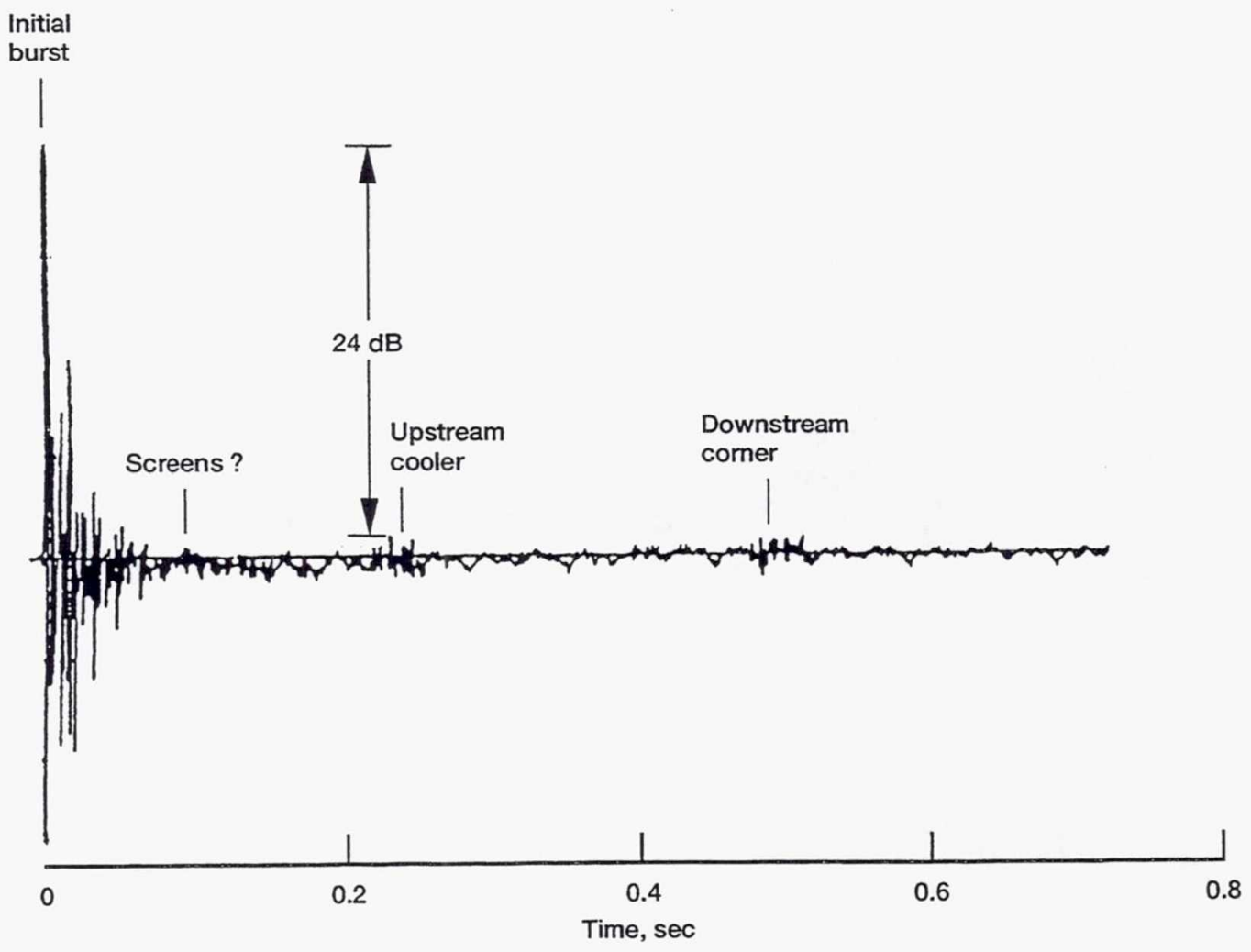

Figure 9.-Acoustic reflection calibration (starter pistol, frequencies up to about $5000 \mathrm{~Hz}$ ). 


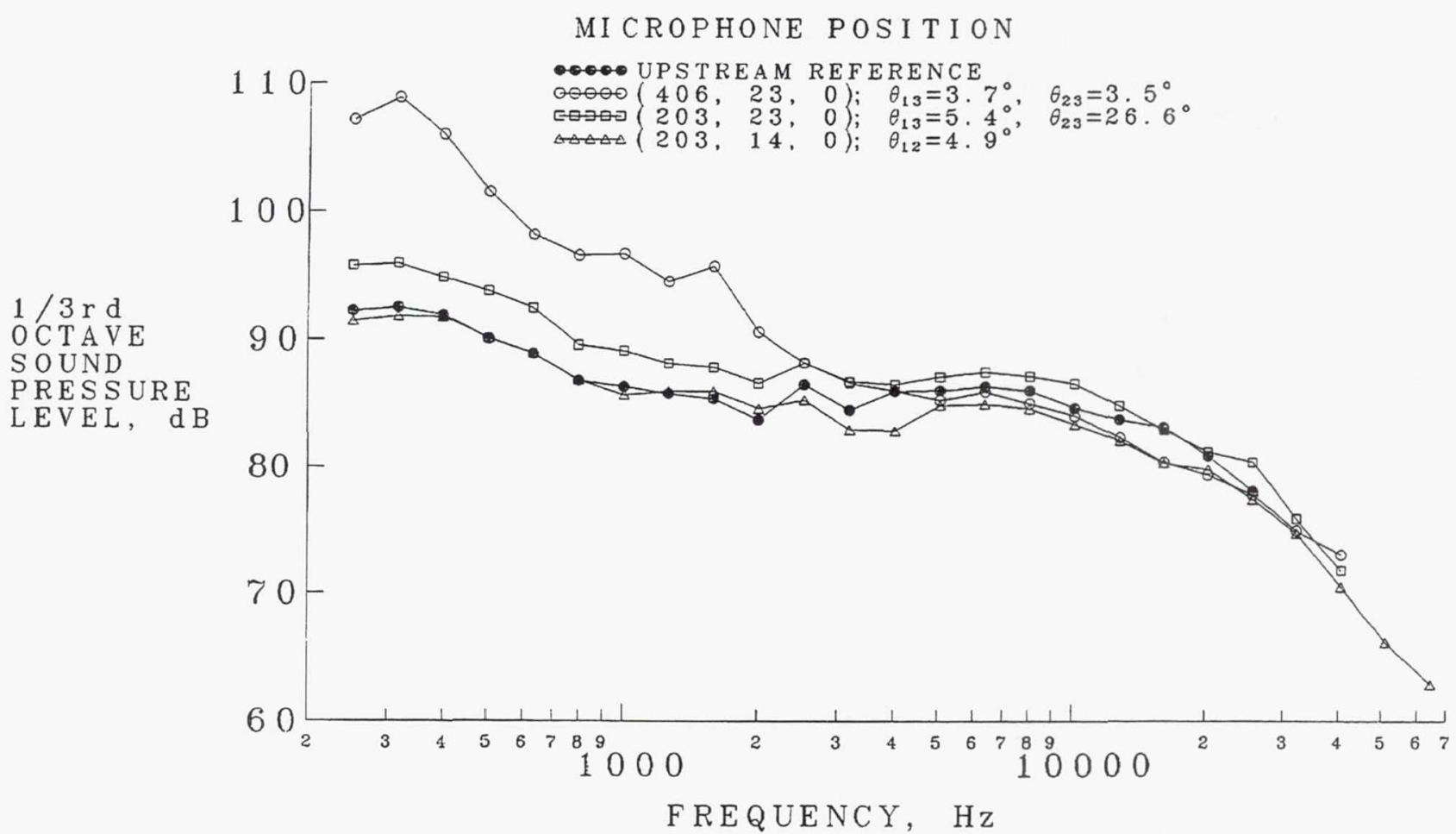

Figure 11.-Effect of microphone holder wakes on downstream background noise levels $(x, y, z$ coordinates in $\mathrm{cm}$ (ref. fig. 11), 0.20 M).

$1 / 3 \mathrm{rd}$

0 C T A V E

SOUND

PRESSURE

LEVEL , dB

MI CROPHONE POSI TION

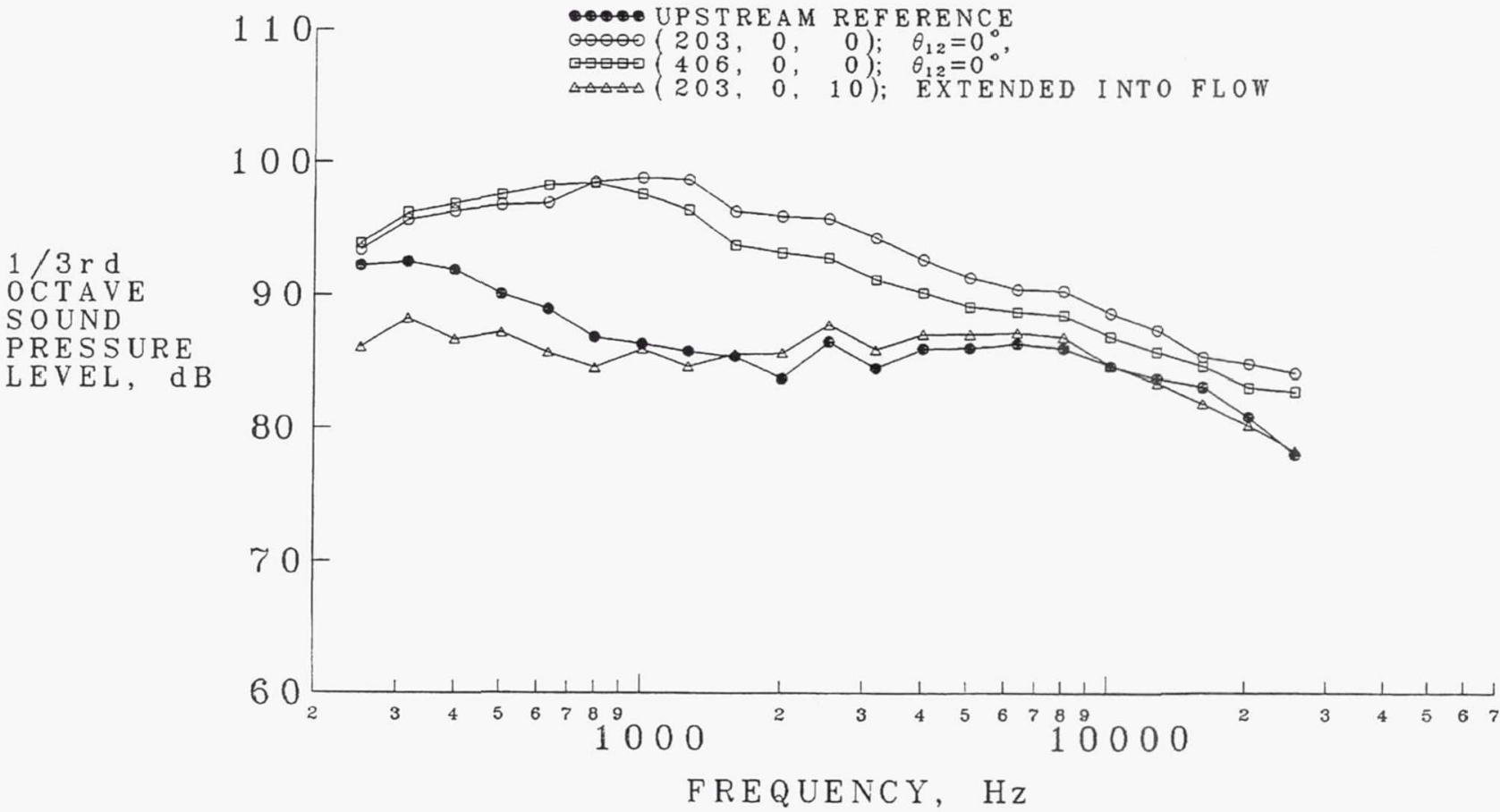

Figure 12.-Effect of microphone holder tip disturbance on downstream background noise levels ( $x, y, z$ coordinates in cm (ref. fig. 11), $0.20 \mathrm{M}$ ). 


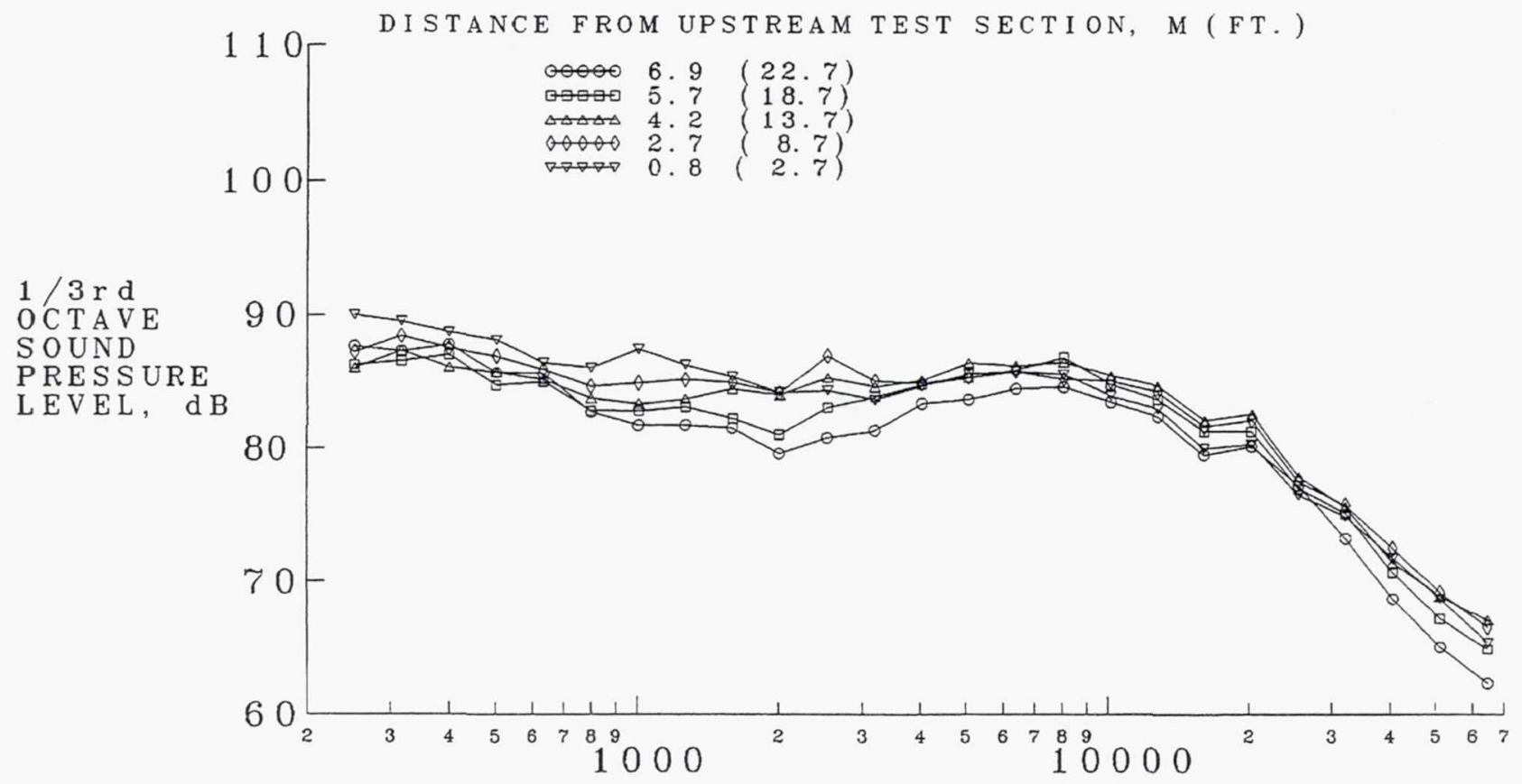

FREQUENCY, Hz

Figure 13.-Tunnel SPL spectra at several axial locations (translating microphone probe data, $0.20 \mathrm{M}$ ).

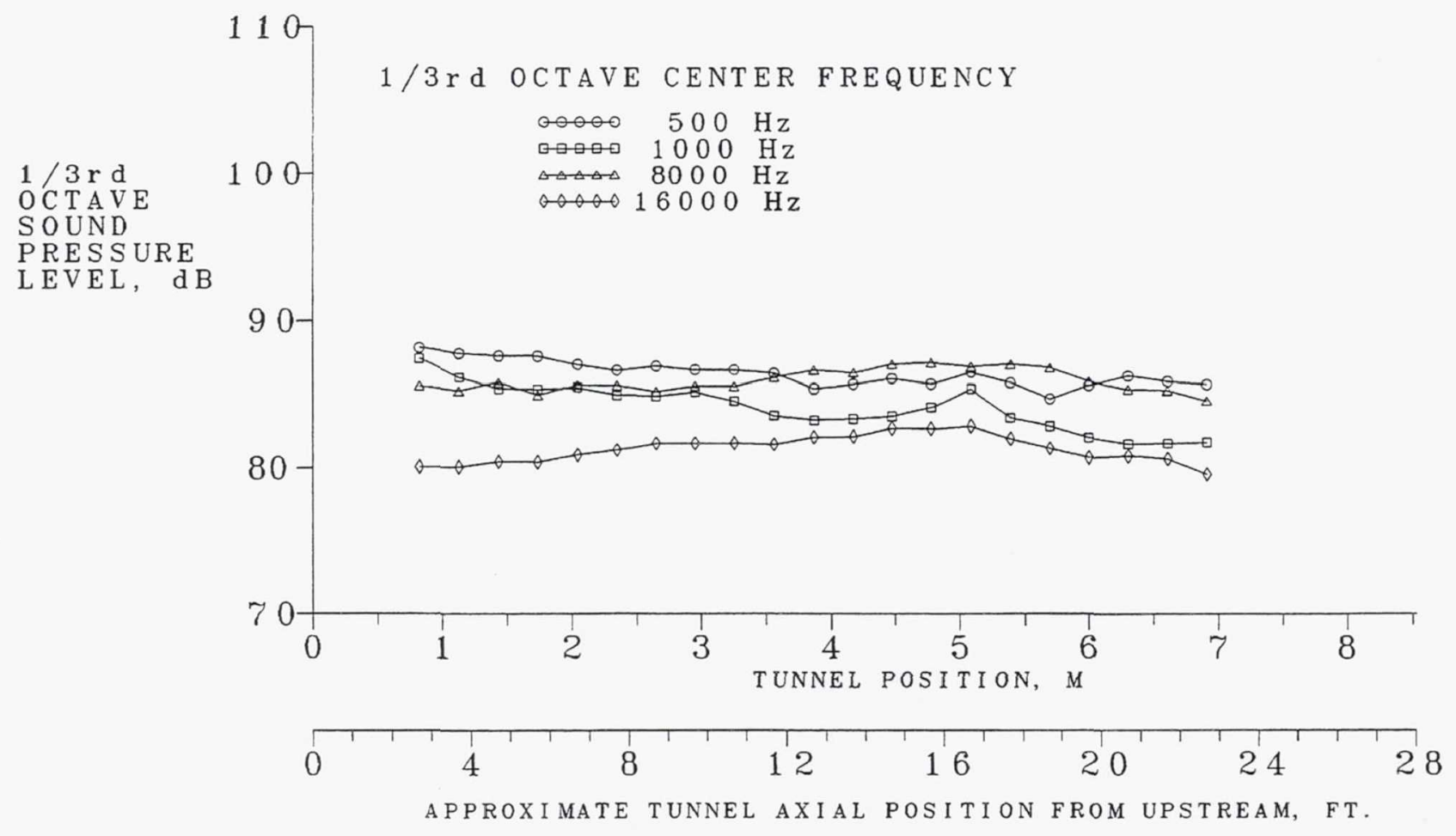

Figure 14.-Tunnel background noise as a function of axial location (translating microphone probe data, 0.20 M). 


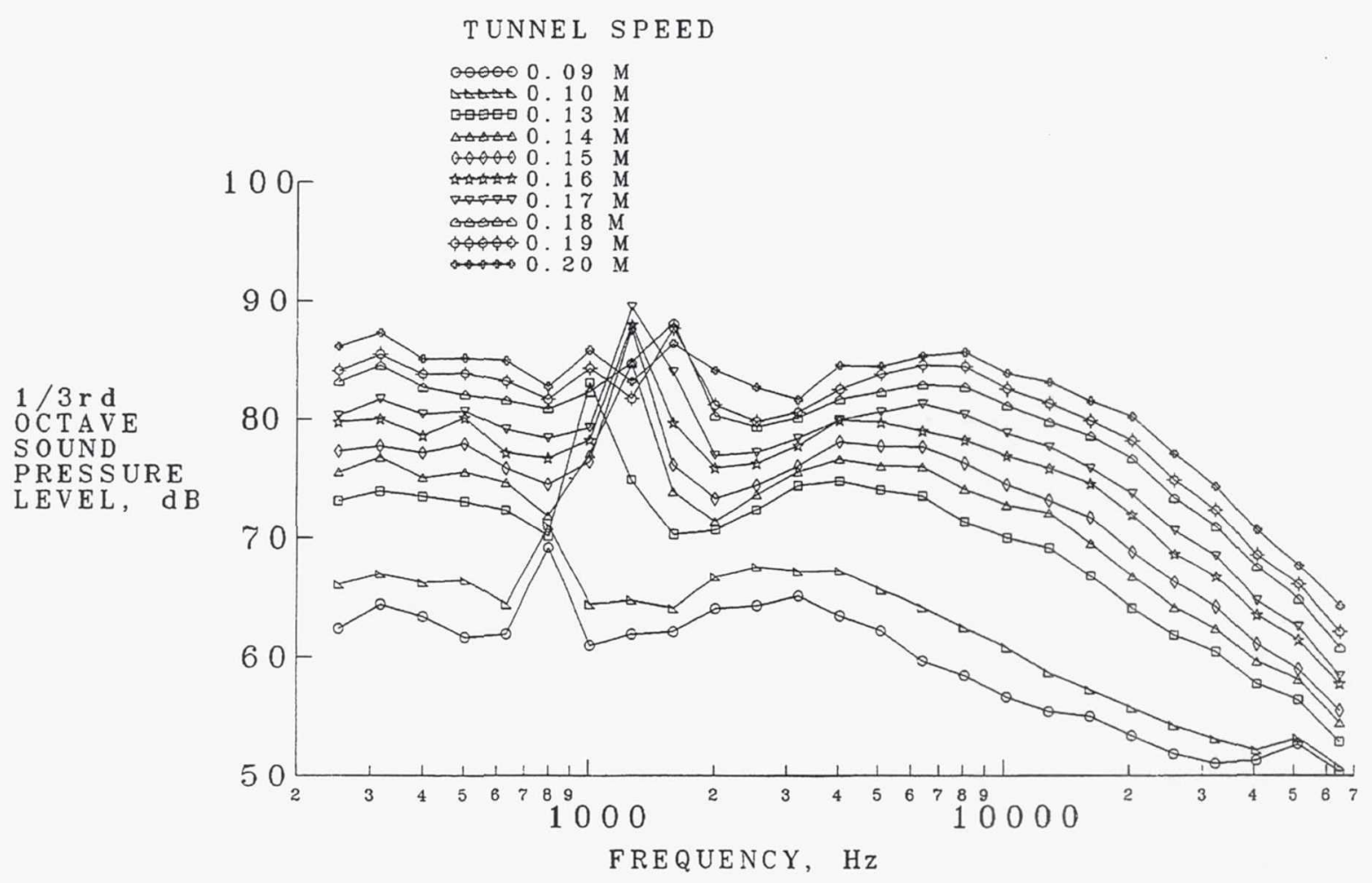

Figure 15.-Identification of test section tone due to presence of tunnel total pressure rake (wall mount, Ames-profile fiberglass holder).

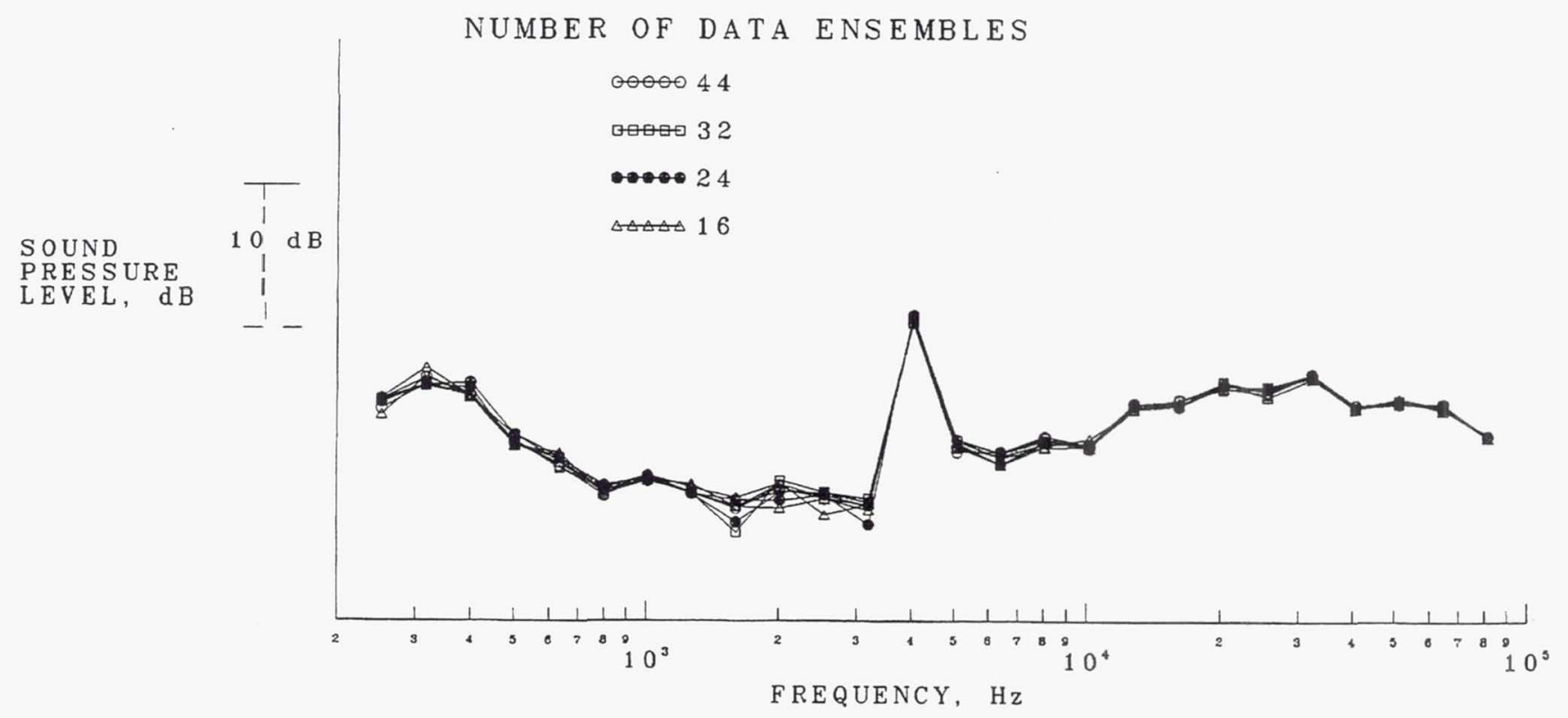

Figure 16.-Repeat 1/3rd octave SPL spectra for model turbofan showing effect of number of data ensembles (fixed wall microphone, $0.20 \mathrm{M})$. 


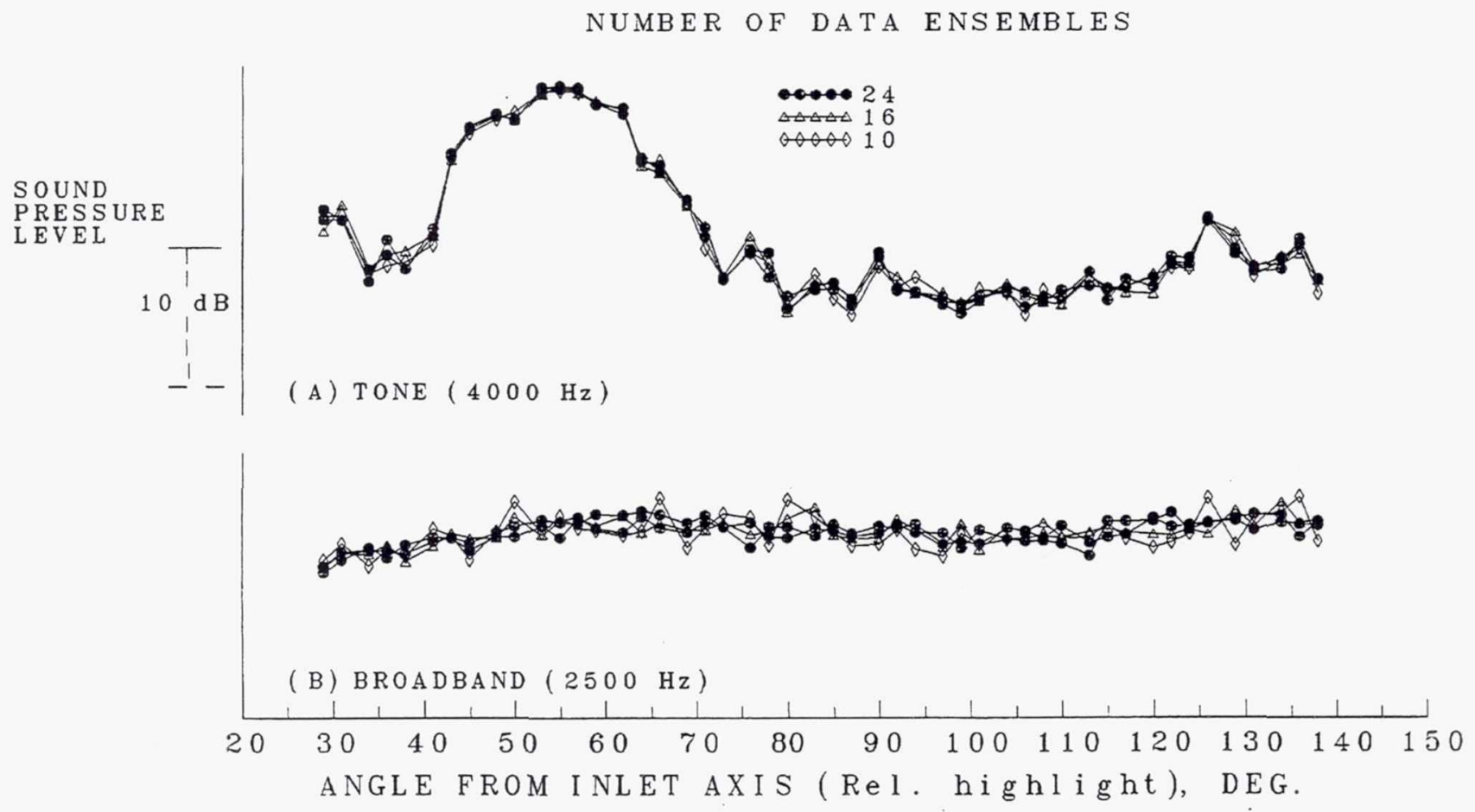

Figure 17.-Sound pressure level directivities for model turbofan taken with the translating microphone probe showing effect of number of data ensembles (1/3rd octave data, $0.20 \mathrm{M}$ ).

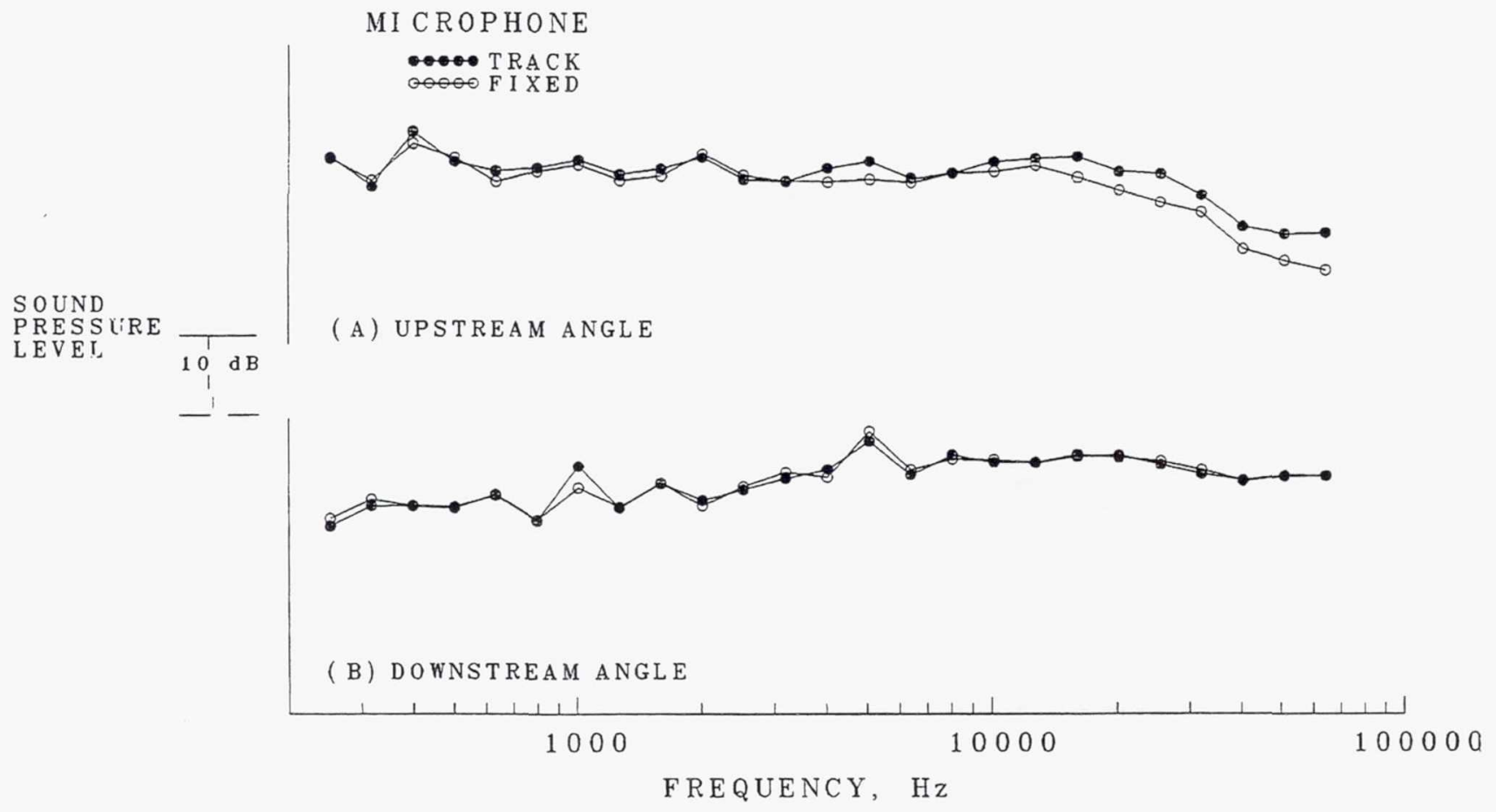

Firgure 18.-Comparison of $1 / 3$ rd octave spectra for model turbofan acquired by fixed microphones and the translating nicrophone probe at common upstream and downstream measuring locations $(0.20 \mathrm{M})$. 
Public reporting burden for this collection of information is estimated to average 1 hour per response, including the time for reviewing instructions, searching existing data sources, gathering and maintaining the data needed, and completing and reviewing the collection of information. Send comments regarding this burden estimate or any other aspect of this collection of information, including suggestions for reducing this burden, to Washington Headquarters Services, Directorate for Information Operations and Reports, 1215 Jefferson Davis Highway, Suite 1204, Arlington, VA 22202-4302, and to the Office of Management and Budget, Paperwork Reduction Project (0704-0188), Washington, DC 20503.

\begin{tabular}{|l|l|r|}
\hline 1. AGENCY USE ONLY (Leave blank) & $\begin{array}{c}\text { 2. REPORT DATE } \\
\text { December } 1994\end{array}$ & $\begin{array}{r}\text { 3. REPORT TYPE AND DATES COVERED } \\
\text { Technical Memorandum }\end{array}$ \\
\hline
\end{tabular}

\section{TITLE AND SUBTITLE}

Background Noise Levels Measured in the NASA Lewis 9- by 15-Foot

Low-Speed Wind Tunnel

\section{AUTHOR(S)}

Richard P. Woodward, James H. Dittmar, David G. Hall, and

Bonnie Kee-Bowling

\section{PERFORMING ORGANIZATION NAME(S) AND ADDRESS(ES)}

National Aeronautics and Space Administration

Lewis Research Center

Cleveland, Ohio 44135-3191

\section{SPONSORING/MONITORING AGENCY NAME(S) AND ADDRESS(ES)}

National Aeronautics and Space Administration

Washington, D.C. 20546-0001
5. FUNDING NUMBERS

WU-538-03-11

8. PERFORMING ORGANIZATION REPORT NUMBER

E-9356

NASA TM-106817

AIAA-95-0720

11. SUPPLEMENTARY NOTES

Prepared for the 33rd Aerospace Sciences Meeting and Exhibit sponsored by the American Institute of Aeronautics and Astronautics, Reno, Nevada, January 9-12, 1995. Richard P. Woodward, James H. Dittmar, and Bonnie Kee-Bowling, NASA Lewis Research Center; David G. Hall, NYMA, Inc., 2001 Aerospace Parkway, Brook Park, Ohio 44142 (work funded by NASA Contract NAS3-27186). Responsible person, Richard P. Woodward, organization code 2770, (216) 433-3923.

12a. DISTRIBUTION/AVAILABILITY STATEMENT

12b. DISTRIBUTION CODE

Unclassified - Unlimited

Subject Categories 07 and 09

This publication is available from the NASA Center for Aerospace Information, (301) 621-0390.

13. ABSTRACT (Maximum 200 words)

The acoustic capability of the NASA Lewis 9 - by 15 -Foot Low Speed Wind Tunnel has been significantly improved by reducing the background noise levels measured by in-flow microphones. This was accomplished by incorporating streamlined microphone holders having a profile developed by researchers at the NASAAmes Research Center. These new holders were fabricated for fixed mounting on the tunnel wall and for an axially traversing microphone probe which was mounted to the tunnel floor. Measured in-flow noise levels in the tunnel test section were reduced by about $10 \mathrm{~dB}$ with the new microphone holders compared with those measured with the older, less refined microphone holders. Wake interference patterns between fixed wall microphones were measured and resulted in preferred placement patterns for these microphones to minimize these effects. Acoustic data from a model turbofan operating in the tunnel test section showed that results for the fixed and translating microphones were equivalent for common azimuthal angles, suggesting that the translating microphone probe, with its significantly greater angular resolution, is preferred for sideline noise measurements. Fixed microphones can provide a local check on the traversing microphone data quality, and record acoustic performance at other azimuthal angles.

\section{SUBJECT TERMS}

Anechoic wind tunnel; Background noise; Acoustic data acquisition

\begin{tabular}{|l|c|}
\hline $\begin{array}{l}\text { 17. SECURITY CLASSIFICATION } \\
\text { OF REPORT }\end{array}$ & $\begin{array}{c}\text { 18. SECURITY CLASSIFICATION } \\
\text { OF THIS PAGE } \\
\text { Unclassified }\end{array}$ \\
\begin{tabular}{c} 
Unclassified \\
\hline
\end{tabular}
\end{tabular}

NSN $7540-01-280-5500$
19. SECURITY CLASSIFICATION OF ABSTRACT Unclassified 